static; but the tempo of industrial progress has so increased, and the changes in industrial methods have become so rapid, that it is now essential that scientific investigation and observation should permeate the day-to-day carrying out of processes, and that in any industrial concern the appropriate knowledge must exist which will enable rapid and useful application to be made of any relevant advances in applied science. The use of instrument recorders and controllers is the prime means of ensuring that such observation and such accumulation of knowledge can be made.

There is little virtue in the mere installation of instruments unless steps are taken to see that the scientific method shall be applied to their use; the installation of instruments may eliminate a large amount of human error, but the whole purpose of the instruments may be defeated unless they are in the charge of technicians who understand the principles of their working and fully appreciate the existence of instrumental errors, which may vary from day to day and with changing physical conditions. Since recorders and controllers are based on physical principles, it would seem logical that the wide introduction of these instruments into industry should be accompanied by an extended use of physicists by industry. It is doubtful whether enough physicists exist to fulfil the requirements of industry, and, in any event, it may well be that the physicists required should have some special instruction and practical technical experience outside the normal university course in physies. While it is to be hoped that facilities for technical education of this type will be available in the future, every encouragement should be given to the younger technical personnel in industry to take advantage of the newly established courses for national certificates in applied physies.

The use of automatic control in the oil industry and in the pasteurization of milk were the subjects of papers by Mr. D. J. Pull and Mr. R. A. Hill, both of which were largely factual statements of the actual systems of automatic controls used in these two spheres. The diverse nature of control is well illustrated by the use of instruments for these two purposes. In the oil industry, when conditions have been achieved such that optimum results are obtained, the paramount need is for a system of control which will prevent any departure from these conditions. An absolute knowledge of, for example, the exact temperatures employed is of secondary importance compared with the rigid maintenance of these temperatures, as only thus can the production of a standard material be assured. In the pasteurization of milk, both an exact knowledge of the temperature and the maintenance of this temperature are essential, since the nutritive value of the milk, and the effectiveness of pasteurization achieved, are vitally dependent upon these factors. The chemical processes of the oil industry are extremely complicated and tend to become progressively more so; and it is evident that the development capacity of instrument manufacturers will be severely strained if instrument design is to keep pace with the control requirements of the industry.

It is perhaps unfortunate that the operation of a controlling mechanism appears to be simple and inexorably exact. The statement, however, that any physical phenomenon, the action of which can be measured, can be used to operate a controller which in turn limits the extent of action of the phenomenon, while generally true, gives no indication of the com- plications which are inherent in any controlling instrument. This point was well illustrated in the papers of Prof. K. A. Hayes and Dr. G. D. Prinz, which dealt with the mathematical analyses involved in studying the characteristics of control systems and of the stability of such systems. The growth in use by industry of what is commonly called instrumentation has been exceedingly rapid, and it is not generally recognized that there is involved in this instrumentation a new branch of technical science, and that knowledge of this technology has probably lagged behind its application. Valuable work on this subject has been carried out by the Servo Panel of the Ministry of Supply during the War, and although the attention of this Panel has naturally been directed towards the problems of control in military usage, as, for example, those inherent in the use of predictors, there is much ground common to these problems and those connected with the control of industrial processes. It would be a pity if knowledge of the valuable work carried out by the Servo Panel were not made available to those responsible for designing, installing and running control systems in industry. If industry is to make full use of instrumental control, as it undoubtedly must do, then it would appear essential that the establishment of courses in technical institutions in the technology of instrument control should be very seriously considered.

In reviewing the proceedings of the Conference, perhaps the most vivid impression left on the mind is the general agreement which exists that the training of physicists is not complete unless it results in students obtaining some knowledge of the more general applications of physics in industry and, in particular, of the use of physical principles in the control of industrial processes. It was urged at the Conference, as indeed it has been urged elsewhere, that the equipment of the ordinary university physics laboratory might well include examples of instrument controls, and that in their practical courses students might examine the performance and limitations of these systems.

The Conference will have been well justified if it has emphasized the urgent necessity for a more general and thorough knowledge of applied physics, and if it has demonstrated that the use of instrument controls in industry is based on a technical science of which knowledge at the moment is far too limited.

\section{PLANT PATHOLOGISTS IN GREAT BRITAIN}

A

REPORT, "The Recruitment and Training of Plant Pathologists in Great Britain", which has been prepared by the Plant Pests and Diseases Committee and adopted by the Council of the Association of Applied Biologists, advocates certain improvements in the training of plant pathologists with a view to a higher and more uniform standard of proficiency at the time of recruitment into the service. The term 'plant pathology' in this report is used in its widest sense to include all disorders of plants, whether caused by insects, fungi, bacteria, viruses, etc.

The plant pathological services in Great Britain have in the main been recruited from graduates of university biological (and to a less extent, chemical) departments who, in the majority of cases, have carried out postgraduate research, usually to the stage of obtaining a Ph.D. degree. This mode of 
training is considered to be too narrow, as it does not give proper emphasis to general aspects of crop husbandry, but tends to produce specialists in disease problems who are insufficiently acquainted with the day-to-day problems of the practical cultivator. Recommendations for an improved course of training are put forward in some detail, the most important of which are as follows.

The basic requirement for an entrant into the profession, whether as research worker or as advisory officer, is held to be the possession of a good university degree in pure science (namely, in botany, zoology or chemistry); but this should be reinforced by a postgraduate course of study in plant pathology which might suitably lead to a diploma in this subject. It is suggested that two years would be ample for such a course. The students, whether intending to become research workers or advisors, and whether entomologists or mycologists, would follow the same course for a considerable period, so that all would possess the same general background, and only in the later part would there be specialization in the various lines of activity. In particular, the importance of considering research workers and advisory officers as equivalent groups and therefore of giving them essentially the same training is stressed. Throughout this course there would be instruction in crop husbandry and in research methods, and facilities would be provided for bringing all students in contact with the practical problems of plant cultivation.

The carrying out of this scheme would be most suitably done in an institute of plant pathology, properly staffed for teaching and for the prosecution of applied research; and with good contacts with the industry on one hand, and with a university on the other. Failing the setting up of such an institute, certain university departments should be strengthened along the lines indicated.

The need for refresher courses for advisors and research workers, for greater provision of technical assistance, and for the grant of scholarships to cover the period of two years postgraduate training is also indicated.

Copies of the report can be obtained from the president of the Association of Applied Biologists, Dr. C. B. Williams, Rothamsted Experimental Station, Harpenden, Herts.

\section{HOSPITAL DIET}

$\mathrm{I}_{\mathrm{p}}^{\mathrm{N}}$ 1943, King Edward's Hospital Fund for London 1 published its first Memorandum on Hospital Diet (Nature, 155, 433; 1945). Since then there has been much constructive criticism. There has been so much demand for the Fund's first memorandum that the Committee on Hospital Diet which it appointed, the chairman of which is Sir Jack Drummond, has now issued a second memorandum (obtainable from G. Barber and Sons, Ltd., 23 Furnival Street, E.C.4, $9 d$.). Everyone who has to cater for groups of people should read it. The housewife, also, will learn much from it.

In many hospitals, says this second memorandum, the importance of good catering is now recognized; but in others it is not. The catering department of a hospital should be regarded as one of the hospital's main departments. It should be a separate unit, administered by a catering officer, who should preferably be a dietitian with adequate experience of large-scale catering. Such dietitians are scarce and more will have to be trained. The catering officer should be responsible for the buying and storage of food, the planning of menus and the cooking and service. This would ensure the unification of the responsibility for catering which is essential. Another essential is direct contact with the food markets and trade, and the memorandum discusses in some detail the buying and storage of foods and the keeping of proper records. The catering officer should be responsible to the governing board through the chief executive officer and through a diet and catering committee; he should co-operate also with the medical staff, who often prescribe special diets as a part of their treatment. The catering officer would thus have considerable responsibility and his office should have appropriate dignity. The diet and catering committee would be technical and professional and would have functions, in its own sphere, similar to those of the medical committee, the ultimate responsibility resting with the board of management.

This committee would not, however, abolish the existing personal relation of the nurse and her patients. Nurses would still serve meals; but the meals would be not only nutritionally sound, but also appetizing and attractive. Such small but important details as the introduction of a little colour into a meal tray by the use of a coloured sauce receive the attention which they deserve. A section of the memorandum is rightly devoted to the diet of the doctors, nurses and others whose work creates for them dietary needs different from those of people who work outside hospitals. The ancillary reforms in the training and efficiency of all grades of kitchen staff also receive adequate consideration.

The committee hopes to see the final abolition of the practice of serving in hospitals only one cooked meal a day, so that relatives and friends of patients would no longer have to bring in supplementary foods. It is odd, however, to find that, among such supplementary foods, eggs and fruit are classed as luxuries. The specimen diets, the seven pages of recipes, the sections on menu-planning and storage of food, the wise advice about salads and raw vegetables, the tables of the nutritive values of various foodstuffs and the valuable section on the destruction of food elements, such as vitamin C, by improper cooking, will interest everyone.

The whole memorandum is so free from the fads and nonsense so often associated with brochures about food that it can be thoroughly recommended.

G. Lapage.

\section{FORTHCOMING EVENTS}

\author{
Saturday, December 15
}

ASSOCIATION OF SCIENTIFIC WORKERS, LEEDS BRANCH (at the Riley-Smith Hall, University Road, Leeds 2), at $2.30 \mathrm{p} . \mathrm{m}$. - Second "The Policy of the Association of Scientific Workers in regard to Science and Education".

SOCIETY OF CHEMICAL INDOSTRY (joint meeting of the FOOD GROUP with the YORKSHIRE SECTION of the S.C.I. and the HULL CHEMICAL AND ENGINEERING SOCIETY, in the Lecture Theatre of the Mining "Hepartment, The University, Leeds), at 3 p.m.-Mr. J. Pryce Jones: "Honey".

\section{Monday, December 17}

NoRth-East COAST INSTITUTION OF ENGINEERS AND SHIPBUILDERS (in the Lecture Theatre, Mining Institute, Newcastle-upon-Tyne), at 6 p.m.-Dr. W. G. Thompson: "Electronies, their Scope in Heavy ROYAL GEOGRAPHICAL SOCIETY (at Kensington Gore, South Kensing-
ton, London, S.W.7), at 8 p.m.- Wing-Commander D. C. McKinley and Wing-Commander R. Winfield: "The Aretic Flights of the Aries". 